\title{
Erratum to: Effect of diet and lifestyle factors on bone health in postmenopausal women
}

\author{
Eman M. Alissa · Sara Ghazi Qadi • \\ Naseem Abdulmohi Alhujaili • \\ Afaf Mohammed Alshehri • Gordon A. Ferns
}

Published online: 7 September 2011

(C) The Japanese Society for Bone and Mineral Research and Springer 2011

\section{Erratum to: J Bone Miner Metab}

DOI 10.1007/s00774-011-0274-8

An error occurred in the listing of the affiliations of the first four authors of the above-cited article. The affiliations should have been shown as:

Center for Excellence for Osteoporosis Research, Faculty of Medicine, King Abdul Aziz University, PO Box 12713, Jeddah 21483, Kingdom of Saudi Arabia

The online version of the original article can be found under doi:10.1007/s00774-011-0274-8.

E. M. Alissa ( $₫)$ · S. G. Qadi · N. A. Alhujaili · A. M. Alshehri Center for Excellence for Osteoporosis Research, Faculty of Medicine, King Abdul Aziz University, PO Box 12713, Jeddah 21483, Kingdom of Saudi Arabia

e-mail: em_alissa@yahoo.com

G. A. Ferns

Institute of Science and Technology in Medicine,

Faculty of Health, University of Keele,

Staffordshire ST4 7QB, UK 